\title{
Aplicação do processo de enfermagem ao paciente acometido por anemia falciforme: relato de experiência
}

\author{
Application of the nursing process to patients affected by sickle cell anemia: \\ experience report
}

\author{
Aplicación del processo de enfermeira a pacientes afectados por anemia \\ drepanocítica: informe de experiencia
}

Zeila Ribeiro Braz ${ }^{1 *}$, João Matheus Ferreira do Nascimento ${ }^{1}$, Ana Clara da Costa Ferreira1, Erielton Gomes da Silva $^{1}$, Yuri Ferreira Fernandes ${ }^{2}$, Danila Barros Bezerra Leal' ${ }^{1}$, Celina César Daniel ${ }^{3}$, Inara Viviane de Oliveira Sena', Maria Sauanna Sany de Moura1, Cinara Maria Feitosa Beleza'.

\section{RESUMO}

Objetivo: Relatar a experiência de acadêmicos de enfermagem na execução do processo de enfermagem adotando as taxonomias NANDA, NIC e NOC aplicadas a paciente acometido por anemia falciforme. Relato de experiência: $O$ presente trabalho trata-se de um relato de experiência referente a um caso identificado durante as aulas práticas da disciplina de saúde da criança e do adolescente. A anamnese e exame físico foram guiados por instrumento de exame físico e semiologia pediátrica. Foram realizadas três visitas ao hospital para avaliação. A criança tem um ano e quatro meses de vida, sexo feminino, branca, pesa 8.700 gramas, mede $82 \mathrm{~cm}, \mathrm{IMC}<$ Percentil 3, em internação no hospital de referência da região. Deu entrada no serviço apresentando palidez cutânea, dor abdominal, abdome distendido e esplenomegalia devido à crise de anemia falciforme. O diagnóstico de anemia falciforme ocorreu aos dois meses de vida através do teste do pezinho. Considerações finais: $O$ presente estudo possibilitou a aplicabilidade prática do Processo de Enfermagem, proporcionando assistência ampliada e centrada na melhora do quadro clínico atual e da qualidade de vida.

Palavras-chave: Anemia falciforme, Pediatria, Assistência de enfermagem.

\begin{abstract}
Objective: To report the experience of nursing students in the implementation of the nursing process adopting the NANDA, NIC and NOC taxonomies applied to patients with sickle cell anemia. Experience report: The present work is an experience report referring to a case identified during practical classes in the discipline of child and adolescent health. The anamnesis and physical examination were guided by an instrument of physical examination and pediatric semiology. Three visits were made to the hospital for evaluation. The child is one year and four months old, female, white, weighs 8,700 grams, measures $82 \mathrm{~cm}$, BMl < 3rd percentile, admitted to the reference hospital in the region. He was admitted to the service with skin pallor, abdominal pain, distended abdomen and splenomegaly due to a sickle cell anemia crisis. The diagnosis of sickle cell anemia was made at two months of life through the heel prick test. Final considerations: This study enabled the practical applicability of the Nursing Process, providing expanded care focused on improving the current clinical condition and quality of life.
\end{abstract}

Key words: Anemia sickle cell, Pediatrics, Nursing care.

\footnotetext{
1 Universidade Federal do Piauí (UFPI), Picos - PI. *E-mail: zeilabraz4.2@gmail.com

2 Universidade Federal do Cariri (UFCA), Barbalha - CE.

${ }^{3}$ Universidade Estadual do Piauí (UESPI), Picos - PI.
} 


\section{RESUMEN}

Objetivo: Informar la experiencia de los estudiantes de enfermería en la implementación del proceso de enfermería adoptando las taxonomías NANDA, NIC y NOC aplicadas a pacientes con anemia falciforme. Informe de experiencia: El presente trabajo es un relato de experiencia referente a un caso identificado durante las clases prácticas en la disciplina de salud infantil y adolescente. La anamnesis y el examen físico fueron guiados por un examen físico pediátrico y un instrumento de semiología. Se realizaron tres visitas al hospital para su evaluación. El niño tiene un año y cuatro meses, es del sexo femenino, blanco, pesa 8.700 gramos, mide $82 \mathrm{~cm}, \mathrm{IMC}<$ percentil 3, ingresado en el hospital de referencia de la región. Ingresó al servicio con palidez cutánea, dolor abdominal, abdomen distendido y esplenomegalia por crisis de anemia falciforme. El diagnóstico de anemia falciforme se realizó a los dos meses de vida mediante la prueba de punción del talón. Consideraciones finales: Este estudio permitió la aplicabilidad práctica del Proceso de Enfermería, brindando atención ampliada enfocada a mejorar la condición clínica actual y la calidad de vida.

Palabras clave: Anemia de células falciformes, Pediatría, Atención de enfermería.

\section{INTRODUÇÃO}

A Doença Falciforme (DF) engloba um grupo de anemias hemolíticas caracterizada por hemácias com formato de foice. Em ambiente de baixa oxigenação, isso dificulta a circulação sanguínea e provoca obstrução de vasos sanguíneos (CASTRO IPS e VIANA MB, 2019). Trata-se de uma doença crônica hereditária, relacionada principalmente às populações originárias da África Subsaariana e países mediterrânenos, contudo encontra-se presente em grande parte da população mundial devido à miscigenação (MINISTÉRIO DA SAÚDE, 2015).

Trata-se de uma das doenças genéticas mais frequentes no Brasil, sendo mais prevalente em regiões em que há maior número de negros, o que se deve ao fato dessa doença acometer sobretudo essa população. Segundo dados do Programa Nacional de Triagem Neonatal (PNTN), do Ministério da Saúde, ao ano nascem no Brasil 3.500 crianças com doença falciforme e 200.000 com traço falciforme (MINISTÉRIO DA SAÚDE, 2015).

O diagnóstico da Anemia Falciforme (AF) é realizado na triagem neonatal, responsável pelo rastreamento da doença em recém-nascidos (MINISTÉRIO DA SAÚDE, 2016). Entre as principais complicações da AF estão o Acidente Vascular Cerebral (AVC), Ataques Isquêmicos Transitórios (AIT), infartos cerebrais silenciosos, desempenho neuropsicológico reduzido, complicações pulmorares agudas, como asma, Síndrome Torácica Aguda (SCA) e risco aumentado de tromboembolismo (ALKINDI S, et al., 2021; MADUAKOR C, et al., 2021).

A doença envolve também elementos psicossociais e de adaptação. Problemas como depressão, ansiedade, comportamento agressivo e medo relacionados à natureza crônica e fatal da doença podem ser frequentes (FÉLIX AA, et al., 2010). A isso, somam-se os fatores socioeconômicos, como as condições de moradia, a qualidade e a quantidade da alimentação ingerida e o nível de atenção à saúde recebido (FIGUEIRÓ AVM e RIBEIRO RLR, 2017).

Não há um tratamento específico para as doenças falciformes. Desse modo, devem ser adotadas medidas preventivas a fim de reduzir as consequências da anemia crônica e suscetibilidade a infecções. Dentre as opções terapêuticas, tem-se a transfusão de glóbulos vermelhos, que melhora a oxigenação dos tecidos e reduz a hemólise (ESTCOURT LJ, et al., 2016). Os cuidadores da criança acometida precisam ser orientados quanto às formas de evitar as crises e identificar os sinais de risco (FIGUEIREDO SV, et al., 2018).

Assim, justifica-se a produção desse estudo pela necessidade de intervir eficazmente a fim de proporcionar melhoria da qualidade de vida em crianças acometidas pela AF, bem como proporcionar orientações aos familiares responsáveis quanto as medidas de promoção do conforto e prevenção de complicações. O objetivo apresentado foi relatar a experiência de acadêmicos de enfermagem na execução do processo de enfermagem adotando as taxonomias North American Nursing Diagnosis Association (NANDA), Network 
Information Center (NIC) e Network Operations Center (NOC), aplicadas a paciente acometido por anemia falciforme.

\section{RELATO DE EXPERIÊNCIA}

O presente trabalho trata-se de um relato de experiência de graduandos de enfermagem na abordagem a caso de anemia falciforme em criança hospitalizada devido à crise. O caso clínico ocorreu durante as aulas práticas da disciplina de saúde da criança e do adolescente.

A anamnese e exame físico foram guiados por instrumento específico. Foram realizadas três visitas ao hospital para avaliação, no turno vespertino. As consultas de Enfermagem viabilizaram a obtenção de um histórico ampliado sobre as condições clinícas da criança e os aspectos socioeconômicos e familiares, nos quais esta se insere, possibilitando a construção do genograma. A elaboração dos diagnósticos, intervenções e resultados de enfermagem ocorreu a partir da análise do histórico clínico e usando as taxonomias NANDAI, NIC e NOC.

\section{Histórico de Enfermagem}

Foi realizada investigação junto à mãe para identificar a origem parental da doença. A criança tem um ano e quatro meses de vida, sexo feminino, branca, pesa 8.700 gramas, mede $82 \mathrm{~cm}$, IMC < Percentil 3 (baixo para a idade), $4^{\circ}$ dia de internação hospitalar, no hospital de referência da região. Deu entrada no serviço apresentando palidez cutânea, dor abdominal, abdome distendido e esplenomegalia devido à crise de anemia falciforme.

O diagnóstico da doença ocorreu aos dois meses de vida. A primeira amostra coletada obteve resultado inconclusivo. A partir da segunda coleta, o diagnóstico foi estabelecido. Segundo Informações Colhidas (SIC), a paciente foi amamentada exclusivamente ao seio até os seis meses e segue em aleitamento materno complementar, possuindo resistência à aceitação de determinados alimentos.

Não possui atraso de desenvolvimento cognitivo. Quanto ao calendário vacinal, este encontra-se atrasado quanto as vacinas Tríplice viral e reforços da Pneumocócica-10 e Meningocócica C. No que diz respeito aos antecedentes familiares, o pai e a mãe apresentam o traço da doença (HbAS). Paciente encontrava-se asseada, com banho realizado uma vez ao dia, pela mãe.

O pai é negro, 20 anos, e trabalha de forma autônoma. A mãe tem 17 anos e é dona de casa. Sobre os antecedentes gestacionais, esta relata ter feito acompanhamento de pré-natal completo, primeira gestação, parto cesário, atermo (40 semanas de gestação), sem intercorrências durante o parto. SIC, é a terceira internação da paciente para tratamento das crises ocasionadas pela doença.

\section{Evolução de Enfermagem}

A primeira visita foi realizada no dia 21 de novembro de 2019, por volta de 08h30min. Foi realizada anamenese e exame físico completo. Paciente com quadro febril e distensão abdominal. Apresenta-se ativa, com estado geral regular, comunicativa, eupnéico, dinâmica e fásica. À inspeção observou-se cabelos bem distribuídos, boa higienização, face simétrica.

Ao exame físico: pupilas isocóricas e fotoreagentes, mucosa nasal, ocular e bucal hidratadas e hipocoradas. Acuidade auditiva e visual preservadas. Pescoço sem gânglios palpáveis. Sono e repouso preservados. Ao exame do aparelho cardiovascular: ausculta cardíaca normal, pulso radial palpável e normocárdico.

Ao exame físico do abdome: ruídos hidroaéreos presentes, percussão abdominal timpânica e abdome distendido. Paciente aceita parcialmente dieta oral para idade. Eliminação urinária fisiológica presente. Paciente apresenta eliminações intestinais ausentes há quatro dias.

Referente aos marcos de desenvolvimento, estes encontram-se presentes. Acesso periférico no MSD. Não refere queixa. Paciente acompanhada da mãe. Esta foi orientada quanto à importância da introd ução de alimentos ricos em folato e outros nutrients; ingesta hídrica adequada; ao uso correto dos medicamentos 
utilizados no domicílio, Pen-ve oral e Folacin; e a necessidade de atualização do calendário vacinal. Quanto aos sinais vitais, a temperatura foi $38.5^{\circ} \mathrm{C}$, pulso: 104 batimentos porminuto e frequência respiratoria: $30 \mathrm{rpm}$.

A segunda visita ocorreu no dia 22 de novembro de 2019, às 09:00h. Paciente com estado geral regular, ativa, eupnéica, afebril, comunicativa. À inspeção observou-se higienização adequada, face simétrica. Ao exame físico: mucosa oral, ocular e nasal hidratadas e hipocoradas. Pupilas fotoreagentes e isocóricas. Quanto à avaliação cardíaca e abdominal: sem alterações. Eliminações vesicais e intestinais fisiológicas e presentes. SSVV: Temperatura: $36.4^{\circ} \mathrm{C}$, Pulso: $90 \mathrm{bpm}, \mathrm{FR}: 35 \mathrm{rpm}$.

Na terceira visita, no dia 22 de novembro de 2019, paciente no $6^{\circ} \mathrm{DIH}$, segue com o estado geral regular, ativa, dinâmica, febril, eupnéica, normotensa, comunicativa, fásica e lúcida. À inspeção observou-se mucosa nasal, ocular, e bucal hidratadas, íntegras e normocoradas. Eliminações vesicais e intestinais fisiológicas e presentes. Paciente aceita dieta oferecida, não refere queixas. SSVV: Temperatura: $38^{\circ}$ C, FC: 105 bpm, FR:35 rpm.

\section{Diagnósticos de Enfermagem}

O cuidado de Enfermagem é direcionado pelas respostas de indivíduos, famílias, grupos e comunidades a problemas de saúde. Um diagnóstico de Enfermagem pode ter como foco um problema real, a promoção de saúde ou um risco em potencial e é subsidiado pela Taxonomia de enfermagem NANDA (HERDMAN TH, 2018).

Os diagnósticos de Enfermagem são imprescindíveis para apoiar os enfermeiros na tomada de decisão sobre os cuidados que devem ser prestados ao paciente (SOUZA PA, et al., 2021). Os diagnósticos estabelecidos para a paciente desse estudo, assim como seus fatores relacionados e características definidoras estão descritos no Quadro 1.

Quadro 1 - Diagnósticos de Enfermagem NANDA.

\begin{tabular}{|c|l|}
\hline \multicolumn{2}{|c|}{ Diagnósticos de enfermagem } \\
\hline Parâmetro & \multicolumn{1}{|c|}{ Taxonomia NANDA } \\
\hline $\begin{array}{l}\text { Nutrição desequilibrada: menor que } \\
\text { as necessidades corporais. }\end{array}$ & $\begin{array}{l}\text { Nutrição desequilibrada evidenciada por ingestão } \\
\text { alimentar insuficiente, caracterizada por interesse } \\
\text { insuficiente pelos alimentos. }\end{array}$ \\
\hline Hipertermia & $\begin{array}{l}\text { Hipertermia evidenciada por doença, } \\
\text { caracterizada por aumento na temperatura } \\
\text { corporal acima dos parâmetros normais. }\end{array}$ \\
\hline Dor Aguda & $\begin{array}{l}\text { Dor Aguda evidenciada por agente biógico } \\
\text { lesivo, caracterizada por alteração no parâmetro } \\
\text { fisiológico. }\end{array}$ \\
\hline Risco de constipação & $\begin{array}{l}\text { Risco de constipação evidenciado por ingesta de } \\
\text { fibras insuficiente. }\end{array}$ \\
\hline Risco de Infecção & $\begin{array}{l}\text { Risco de infecção evidenciado por vacinação } \\
\text { inadequada. }\end{array}$ \\
\hline
\end{tabular}

Fonte: BRAZ ZR, et al., 2021; Dados baseados no Livro NANDA (HERDMAN TH, 2018).

\section{Intervenções de Enfermagem}

As intervenções de Enfermagem são definidas como qualquer tratamento que o enfermeiro, fundament ado em evidências científicas, implementa para intensificar os resultados do paciente. (DOCHTERMAN JM e BULECHEK GM, 2016).

A taxonomia NIC possibilita a determinação e nomeação das ações que devem ser executadas para prescrever e melhorar a saúde do paciente (KOCAÇAL E e KARADAG E, 2020). No Quadro 2 estão listadas as intervenções para cada diagnóstico. 
Quadro 2 - Intervenções de enfermagem NIC.

\begin{tabular}{|c|c|}
\hline \multicolumn{2}{|c|}{ Intervenção de enfermagem } \\
\hline Parâmetro & Taxonomia Nic \\
\hline $\begin{array}{l}\text { Nutrição desequilibrada: menor que as } \\
\text { necessidades corporais }\end{array}$ & Aconselhamento nutricional; controle hídrico. \\
\hline Hipertermia & Monitorização dos sinais vitais; \\
\hline Dor Aguda & $\begin{array}{l}\text { Controle do ambiente: conforto; administração de } \\
\text { medicamentos: endovenosa. }\end{array}$ \\
\hline Risco de constipação & Planejamento da dieta; \\
\hline Risco de Inf ecção & $\begin{array}{l}\text { Identificação de riscos; controle de imunização/ } \\
\text { vacinação. }\end{array}$ \\
\hline
\end{tabular}

Fonte: BRAZ ZR, et al., 2021; Dados baseados no Livro NIC (DOCHTERMAN JM e BULECHEK GM, 2016).

\section{Resultados de Enfermagem}

Segundo Moorhead S, et al. (2016), os resultados dizem respeito à resposta do indivíduo, família ou comunidade às intervenções implementadas e ajudam na determinação da necessidade de mudança ou continuidade dos cuidados implementados (CAVALCANTE AMRZ, et al., 2020). Os resultados esperados para a paciente desse estudo estão listados no Quadro 3.

Quadro 3 - Resultados esperados NOC.

\begin{tabular}{|c|c|}
\hline \multicolumn{2}{|c|}{ Resultado de enfermagem } \\
\hline $\begin{array}{c}\text { Parâmetro } \\
\begin{array}{l}\text { Nutrição desequilibrada: menor que as } \\
\text { necessidades corporais }\end{array}\end{array}$ & $\begin{array}{l}\text { Estado nutricional: ingestão de alimentos } \\
\text { e líquidos; }\end{array}$ \\
\hline Hipertermia & Termorregulação; \\
\hline Dor Aguda & Controle da dor; \\
\hline Risco de constipação & Conhecimento: estilo de vida saudável; \\
\hline Risco de Infecção & Controle de riscos. \\
\hline
\end{tabular}

Fonte: BRAZ ZR, et al., 2021; Dados baseados no Livro NOC (MOORHEAD S, et al., 2016).

\section{Genograma Familiar}

Após a realização da coleta de dados acerca da situação clínica da criança, buscou-se informações sobre os antecedentes familiares e sociais a fim de investigar as condições nas quais a doença se desenvolveu. A partir disso, foi possível elaborar um genograma como ferramenta para compreender como o histórico familiar culminou na referida doença.

Com o intuito de garantir a confidencialidade dos dados dos participantes do estudo, os nomes foram substituídos por letras aleatórias, referenciados como: JRSF, SGS, DASP, SRSP, JMS, SES, DSSP, RSP, e ASS. As informações destacadas foram analisadas e ilustradas mediante a apresentação da Figura 1, resultado da montagem do genograma familiar.

O genograma pode ser descrito como: pessoa JRSF teve um relacionamento com a pessoa SGS, o que originou dois filhos do sexo masculino, SES e JMS. A pessoa SES casou-se com a pessoa DSSP, ambos com traço para AF, dando origem à criança portadora da AF, ASS.

A relação entre o casal, SES e DSSP, é harmoniosa e estavel. SES autodeclara-se negro e trabalha de forma autônoma. A DSSP, mãe da criança, autodeclara-se branca e é dona de casa. 
Figura 1 - Genograma familiar de identificação dos fatores hereditários para HbSS.
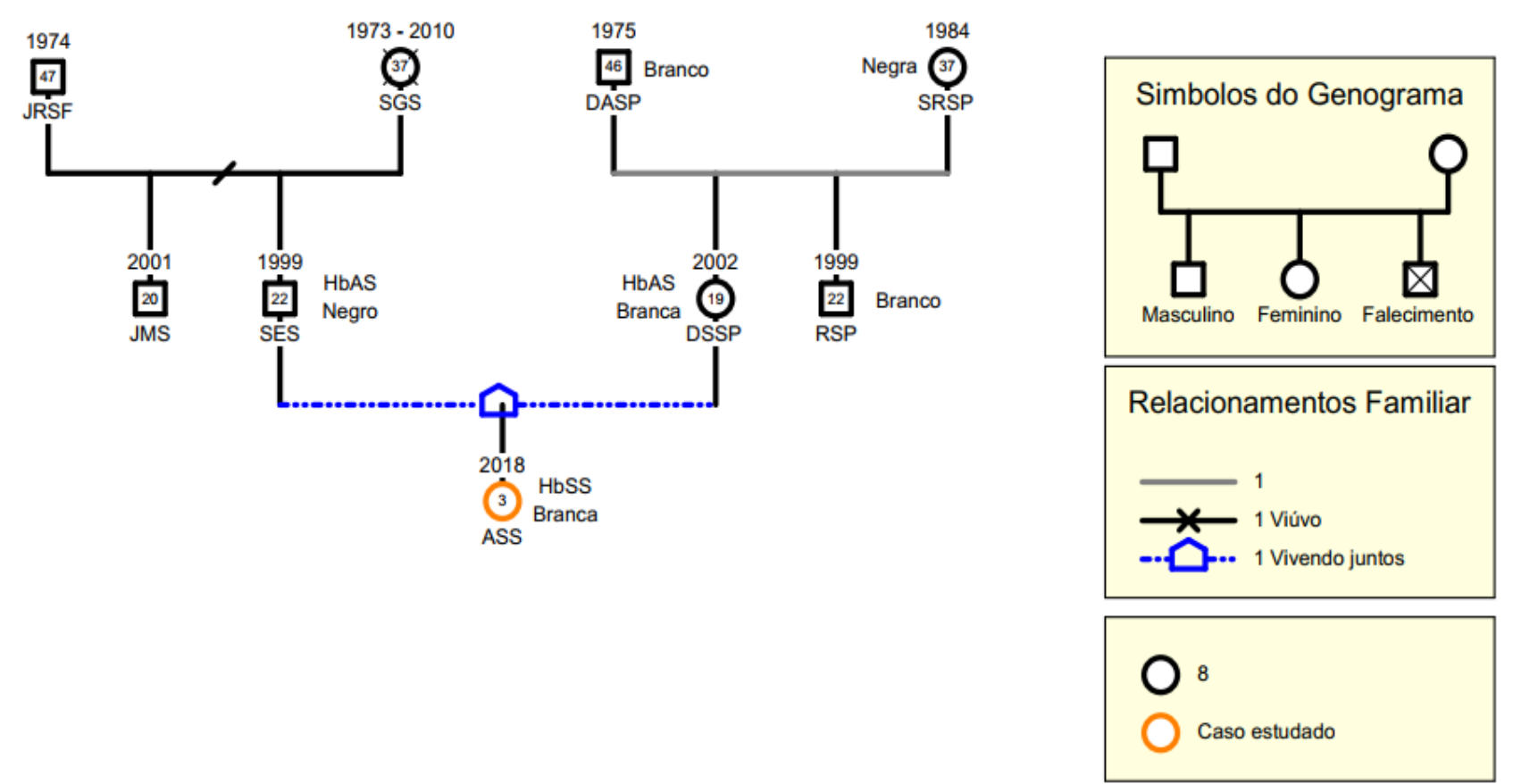

Fonte: BRAZ ZR, et al., 2021; utilizado o programa: GenoPró, 27.

\section{DISCUSSÃO}

A AFocorre devido uma modificação genética em que há a substituição da base nitrogenada timina pela adenina, em que finda na substituição do aminoácido ácido glutâmico por valina, na posição seis da cadeia $\beta$ no braço curto do cromossomo 11. Essa alteração forma a hemoglobina estruturalmente anormal, chamada de hemoglobina $\mathrm{S}(\mathrm{HbS})$, que leva à transformação e ao endurecimento da membrana da hemácia (JESUS ACS, et al., 2018).

No Brasil, a AF é reconhecida como uma das doenças hereditárias mais comuns e a mais grave dentre as DF, considerada um grave problema de saúde pública pela World Health Association (WHO) e a Organização das Nações Unidas (ONU). A doença af eta tanto os sistemas fisiológicos quanto cognitivos, resultando em crises de dor, febre (ARDUINI GAO, et al., 2017; DEOTTO A, et al., 2018).

Nesse sentido, crianças com AF enfrentam importantes problemas durante a infância, dentre os quais destaca-se a diminuição da velocidade de processamento da informação, caracterizada por um maior tempo de resposta motora em múltiplas tarefas, quando comparada a crianças sem diagnóstico da doença. É evidenciada assim a necessidade de inserir na rotina dessas crianças avaliações cognitivas que permitirão direcionar intervenções no ambiente escolar para auxiliar docentes e equipe pedagógica quanto a prevenção e reabilitação (CASTRO IPS e VIANA MB, 2019; MARINELLO KCV, et al., 2021).

Nesta doença as hemácias adquirem formato de foice ou meia lua, ao invés do padrão de normalidade, que são eritrócitos globosos. As hemácias em forma de foice são mais rígidas e sobrevivem na circulação sanguínea por menos tempo que os eritrócitos normais, permanecendo em média por 10 dias, muito menos que o tempo médio usual de 120 dias. Assim, estas estão mais propensas à hemólise, o que resulta em anemia crônica intensa (MINISTÉRIO DA SAÚDE, 2015).

A aparência em foice das hemácias resulta em eventos importantes na fisiopatologia da doença, são eles: vaso-oclusão e hemólise. A AF pode apresentar-se na forma homozigótica, que é a manifestação grave da doença (HbSS - anemia falciforme), em associação com outras hemoglobinas: HbSC, HbSD, HbSE e S $\beta$ talassemia $(S \beta+$ e $S \beta 0)$; e na forma heterozigótica ( $\mathrm{HbAS}$ - traço falciforme), na qual não há manifestação clínica e nem requer tratamento (SARAT CNF, et al., 2019). 
Nesse sentido, Santana DM, et al. (2020) enfatizam a relevância do profissional Enfermeiro no acompanhamento de pacientes com distúrbios hereditários nos diferentes níveis de atenção à saúde. Seja na atenção básica no aconselhamento genético, nas consultas de pré-natal, no puerpério, na triagem neonatal, nas exacerbações da doença a fim de garantir intervenções oportunas e eficazes.

O quadro clínico da AF inclui crises dolorosas, agudas ou crônicas, palidez, cansaço excessivo, icterícia, úlceras nas pernas e maior suscetibilidade à infecções (DOUAMBA S, et al., 2017; TOLEDO SLO, et al., 2019). Dentre as complicações da doença pode-se mencionar o AVC isquêmico, que predomina em crianças (SANTOS EC, et al., 2019). Nesse sentido, há uma série de implicações da AF na saúde e na qualidade de vida da criança af etada e da família.

O peso corporal, o IMC e a ingesta inadequada de nutrientes específicos podem af etar a gravidade da doença falciforme, interferindo no número e duração de internações (MANDESE V, et al., 2016). Desse modo, crianças com DF requerem atenção clínica e nutricional ampliada, haja vista que as crises dolorosas podem causar sofrimento intenso, reduzindo o consumo de alimentos. Ademais, a família pode se sentir insegura quando ao tipo de alimentação que deve ser of ertada à criança, o que pode limitar as fontes de nutrientes. (SANTOS IN, et al., 2018).

O advento da triagem neonatal, a profilaxia antibiótica, imunização, maior segurança nas transfusões sanguíneas, quelação de ferro e a terapêutica com a hidroxiureia melhoraram a sobrevida dos pacientes com DF, reduzindo a mortalidade (ELMARIAH H, et al., 2014). Em seu estudo, Dias PAR, et al. (2020) enfatizam o Transplante de Células-Tronco Hematopoiéticas (TCTH) como única possibilidade de cura em pacientes pediátricos com anemia falciforme, que não tem cura por meio de outros tratamentos.

Assim, a execução do presente estudo possibilitou a aplicabilidade prática do Processo de Enfermagem a paciente com anemia falciforme, proporcionando uma assistência ampliada e centrada tanto na melhora do quadro clínico atual, quanto na melhoria da qualidade de vida no cotidiano da criança, visando um desenvolvimento físico e cognitivo adequado e limitação das repercussões negativas da doença sobre a saúde e bem-estar da criança e da família.

\section{REFERÊNCIAS}

1. ARDUINI GAO, et al. Mortality by sickle cell disease in Brazil. Rev. Bras. Hematol. Hemoter., 2017;39(1):52-56.

2. ALKINDI S, et al. Predicting risk factors for thromboem bolic complications in patients with sickle cell anaemia - lessons learned for prophylaxis. J of International Medical Research, 2021;49(11):1-11.

3. CASTRO IPS, VIANA MB. Cognitive profile of children with sickle cell anemia compared to healthy controls. J Pediatr., 2019; 95(4): 451-457.

4. CAVALCANTE AMRZ, et al. Validação de definições para indicadores do resultado NOC: Autocontrole da doença cardíaca. Acta Paul Enferm., 2020; 33(1):1-9.

5. DEOTTO A, et al. Does stroke impair academic achievement in children? The role of metacognition in math and spelling outcomes following pediatric stroke. Journal of Clinical and Experimental Neuropsychology, 2018;41(3):257-269.

6. DIAS PAR, et al. Influência do transplante de células tronco hematopoiéticas na qualidade de vida de pacientes pediátricos. Rev. Eletrônica Acervo Científico, 2020;14(1):1-7.

7. DOCHTERMAN JM, BULECHEK GM. Classificação das Intervenções de Enfermagem (NIC). 6ª ed. Porto Alegre: Artmed, 2016.

8. DOUAMBA S, et al. Syndromes drépanocytaires majeurs et infections associées chez l'enfantau Burkina Faso. Pan African Medical Journal, 2017;26(7): 1-6.

9. ELMARIAH H, et al. Factors associated with survival in a contemporary adult sickle cell disease cohort. American Journal of Hematology, 2014;89(5):530-535.

10. ESTCOURT LJ, et al. Regular long-term red blood cell transfusions for managing chronic chest complications in sickle cell disease (Review). Cochrane Database of Systematic Reviews, 2016;5(1): 1 -23.

11. FÉLIX AA, et al. Aspectos epidemiológicos e sociais da doença falciforme. Rev. Bras. Hematol. Hemoter. 2010;32(3): 203-208.

12. FIGUEIREDO SV, et al. Importância das orientações em saúde para familiares de crianças com doença falciforme. Rev. Bras. Enferm., 2018;71(6): 2974-82.

13. FIGUEIRÓ AVM, RIBEIRO RLR. Vivência do preconceito racial e de classe na doença falciforme. Saúde Soc., 2017; 26(1): 88-99.

14. HERDMAN TH, Diagnósticos de enfermagem da NANDA: definições e classificação 2018-2020. Porto Alegre: Artmed, 2018.

REAS | Vol. 15 (1) | DOI: https://doi.org/10.25248/REAS.e9499.2022 
15. JESUS ACS, et al. Características socioeconômicas e nutricionais de crianças e adolescentes com anemia falciforme: uma revisão sistemática. Rev. Paul. Pedriatr., 2018; 36(4):491-499.

16. KOCAÇAL E, KARADAG E. Nursing diagnoses and NIC interventions in adult males undergoing radical prostatectomy. Rev. Esc. Enferm. USP, 2020; 54(1): 1-8.

17. MADUAKOR C, et al. The Epidemiology of Neurological Complications in Adults With Sickle Cell Disease: A Retrospective Cohort Study. Front Neurol., 2021; 12(747118):1-7.

18. MANDESE V, et al. Effects of nutritional intake on disease severity in children with sickle cell disease . Nutrition Journal, $2016 ; 15(46): 1-6$.

19. MARINELLO KCV, et al. Avaliação do tempo de reação em crianças com anemia falciforme, Motricidade, Rev. Motricidade, 2021;17(1): 7-14.

20. MINISTÉRIO DA SAÚDE. Secretaria de Atenção à Saúde. Departamento de Atenção Hospitalar e de Urgência. Doença falciforme: diretrizes básicas da linha de cuidado. 2015. Disponível em: https://bvsms.saude.gov.br/bvs/publicacoes/doenca_falciforme_diretrizes_basicas_linha_cuidado.pdf. Acessado em: 8 de novembro de 2020

21. MINISTÉRIO DA SAÚDE. Secretaria de Atenção à Saúde. Departamento de Atenção Especializada e Temática. Biological neonatal screening: technical manual. 2016. Disponível em: http://bvsms.saude.gov.br/bvs/publicacoes/triagem_neonatal_biologica_manual_tecnico.pdf. Acessado em: 27 de november de 2019.

22. MOORHEAD S, et al. Classificação dos Resultados de Enfermagem (NOC): mensuração dos resultados em saúde. $5^{\mathrm{a}}$ ed. Rio de Janeiro: Elsevier, 2016.

23. SANTANA DM, et al. Mortalidade por transtornos falciformes no estado da Bahia no período de 2012 a 2016 . Revista Eletrônica Acervo Saúde, 2020;12(12): 1-8.

24. SANTOS EC, et al. Acidente Vascular Cerebral em pacientes portadores de Anemia Falciforme. Revista Eletrônica Acervo Saúde, 2019;32: 1-8.

25. SANTOS IN, et al. Food insecurity and social support in families of children with sickle-cell disease. J Pediatr (Rio J), 2018;3(95): 306-313.

26. SARAT CNF, et al. Prevalência da doença falciforme em adultos com diagnóstico tardio. Acta Paul Enferm. 2019; 32(2): 202-209

27. SOUZA PA, et al. Nursing diagnoses of impaired memory chronic confusion for older adults: diagnostic content validation. Rev. Bras. Enferm., 2021;74(2): 1-8.

28. TOLEDO SLO, et al. Avaliação da qualidade de vida de pacientes com Doença Falciforme. Rev. Med. Minas Gerais, 2020;30(1): 1-8. 